\title{
First International One Health congress
}

\begin{abstract}
Author:
Martyn H. Jeggo ${ }^{1}$

Affiliation:

${ }^{1}$ Australian Animal Health

Laboratory, Victoria, Australia

Correspondence to:

Martyn Jeggo

Email:

martyn.jeggo@csiro.au

Postal address:

Australian Animal Health Laboratory, CSIRO Livestock Industries, PMB 24, Geelong Vic 3220

How to cite this abstract: Jeggo, M.H., 2012, 'First International One Health congress', Onderstepoort Journal of Veterinary Research 79(2), Art. \#471, 1 page. http://dx.doi. org/10.4102/ojvr.v79i2.471

Note:

Proceedings of the Conference of the Southern African Centre for Infectious Disease Surveillance 'One Health' held at the National Institute for Communicable Diseases, Johannesburg, July 2011.
\end{abstract}

More than 650 people from around 60 countries attended the 1st International One Health Conference, held in Melbourne from 14 to 16 February 2011. Scientists, clinicians, government and community members from a range of disciplines came together to discuss the benefits of working together to promote a One Health approach to human, animal and environmental health. One Health embraces systems thinking and recognising the interdependence of people, animals and environment. The conference was hosted by the Commonwealth Scientific and Industrial Research Organisation (CSIRO) and was supported by international agencies, the Australian and Canadian governments, and industry.

The Organising Committee recognised from the outset, the need to provide a forum not just for scientific presentation, but for open discussion and dialogue around the policy and political issues, as well as the science that drives the One Health agenda. The Committee was also cognizant of the need to embrace a definition of One Health that includes food security and food safety and included the social and economic pressures that shapes this area. The meeting was therefore organised under four themes with plenary sessions followed by breakout parallel sessions for each of these. The themes covered Disease Emergence, Environmental Drivers, Trade, Food Security and Food Safety, and Science Policy and Political Action. The plenary session commenced with one or two keynote presentations by world leaders on the topic being covered, followed by panel discussions involving six to eight experts and involving all participants at the congress. Each of the panel members spoke briefly on the topic covered by the keynote speaker and were asked to be as provocative as possible. The discussions that followed allowed debate and discussion on the keynote presentations and the panel members comments. This was followed by six to eight parallel breakout sessions involving in depth papers on the session's topic. Throughout the conference at various times, sponsored sessions dealt with particular areas of science or policy providing a further framework not only to learn current science but for debate and discussion. A full copy of all abstracts is available on the web at http://www.springerlink.com.

In concluding the Congress recognised the interdependence of, and seeks to improve human, animal and environmental health; recognised that communication, collaboration and trust between human and animal health practitioners is at the heart of the One Health concept; agreed that a broad vision that includes other disciplines such as economics and social behaviour is essential to success. The Congress stressed the need to promote the 'do-able' such as improving surveillance and response for emerging infectious diseases whilst developing the broader approach. It identified a need to emphasise community participation and development of community capacity, and especially, an open transparent dialogue with both a 'ground up' and 'top down' approach that would lead to an improved understanding of our ecosystems, including molecular ecobiology, are an essential part of One Health.
(C) 2012. The Authors. Licensee: AOSIS OpenJournals. This work is licensed under the Creative Commons Attribution License. 